\title{
Editorial
}

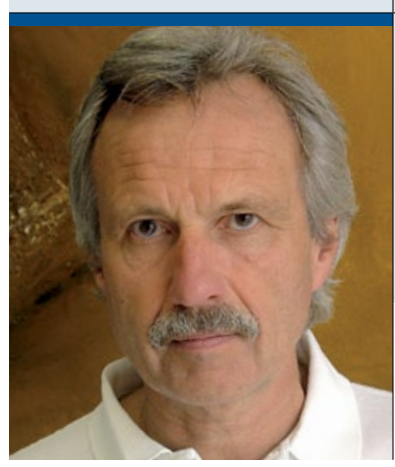

"Das Wartezimmer bietet unseren Patienten jede Menge

Kurzweil und Bildung - und das gänzlich kostenlos!"

Dr. med. Michael Pieper (Chefredakteur),

Orthopäde am Endocenter Damme

\section{Lange Wartezeiten für Patienten? Ein wahrer Segen!}

$\mathrm{D}$ a hatten die Gesetzlichen Krankenversicherungen zum Ende des vergangenen Jahres den Geistesblitz, wie man schnell noch eine kleine Schlammschlacht entfesseln kann, um von eigener Unfähigkeit abzulenken. „Ausbeutung der Kassenpatienten zugunsten der Privatpatienten“ lautete das hierfür auserkorene Thema. Der Privatpatient wird bevorzugt bedient, der Kassenpatient muss leidend ewig warten. Die Kassenonkels sehen den Sicherstellungsauftrag in Gefahr. Den Klassenkampf als Markenzeichen wiederentdeckend, wittert die SPD: Die Zweiklassenmedizin droht! Ausbeutung der Werktätigen durch die Geisteselite! Die Privatkassen sind Schuld!

Eine postwendende Umfrage der Kassenärztlichen Bundesvereinigung zufolge und einer weiteren des Finanzdienstleisters MLP zusammen mit der Bundesärztekammer spielen bei der überwiegenden Zahl der Patienten Wartezeiten eher keine prekäre Rolle. Dies möglicherweise auch, weil die Beschwerden, die einen Maladen um einen Arzttermin nachsuchen lassen, mit dem Überleben zumeist durchaus vereinbar sind.

\section{Warten - Wellness inklusive}

Und was heißt länger auf einen Termin warten oder längere Wartezeiten ertragen müssen? Genießen kann der Patient, genießen! Sind doch in aller Regel trotz budgetärer Restriktionen, die notwendig sind, um den Verwaltungsapparat der Kassen größer, effizienter und schöner zu gestalten, die Aufenthaltsräume für Patienten in den Praxen geheizt und mit Sitzgelegenheiten versehen. Davon können zum Beispiel Bahnreisende nur träumen - jedenfalls jene, die nicht erster Klasse gebucht haben. Damit der Patient sich nicht verirrt oder auf dumme Gedanken kommt, steht auch noch angeschrieben „Wartezimmer“. Unzweideutig heißt das, man darf hier warten. Und das ganz umsonst. Keine Gebühr für alle Zeit der Welt. Zu allem Guten ist auch für Kurzweil und Bildung gesorgt: Es gibt kostenlos Zeitschriften, teilweise sogar Fernsehen.

\section{Warten bildet}

Und Fortbildung tut Not. Schließlich muss der Patient künftig gemäß dem in Arbeit befindlichen $\mathrm{Pa}$ tientenrechtegesetz mündig auf Augenhöhe die eigene Behandlung mitentscheiden. Nein, er braucht nicht auf einen Hocker steigen oder sich bücken, um dem Arzt in die Augen schauen zu können. Er muss seinen Grips trainieren, um zu verstehen, wozu der andere etliche Jahre an der Uni rumgewurstelt hat. So bietet sich im Wartezimmer (entsprechende Fortbildungsangebote vorausgesetzt: vielleicht Apotheken Umschau, Dr. House oder Emergency Room) Gelegenheit zum Selbststudium. Auch die übrigen Qualitäten des ärztlichen Gastgebers lassen sich im Kreise Gleichgesinnter besser diskutieren: Wie steht es denn mit Arbeitsunfähigkeitsbescheinigungen, Verordnungen von Massage et cetera?

\section{Ende gut, alles gut}

Eine längere Wartezeit hat zudem durchaus auch therapeutischen Nutzen. So mancher Patient, der vielleicht alle Zeitschriften schon kennt und auch keinen Bekannten zum Klönen getroffen hat, verlässt die Praxis mit den Worten: „Das dauert mir jetzt aber doch zu lange, ich komme morgen wieder.“ Nicht drohen, denkt der geneigte Zuhörer, besonders wenn sich die Besuche im Quartal häufen. So hat die Wartezeit allen genutzt: den Beschwerden, den Nerven, dem Budget.

Es grüßt Sie Ihr

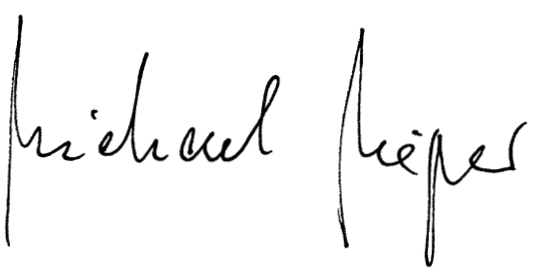

